\title{
RESPONSIVENESS TO THE PORTUGUESE VERSION OF THE INTERNATIONAL CONSULTATION ON INCONTINENCE QUESTIONNAIRE - SHORT FORM (ICIQ-SF) AFTER STRESS URINARY INCONTINENCE SURGERY
}

\author{
JOSE T. N. TAMANINI, MIRIAM DAMBROS, CARLOS A. L. D’ANCONA, PAULO C. R. \\ PALMA, N. RODRIGUES-NETTO JR
}

Center for Prevention and Treatment of Urogynecological Dysfunction, Jau, and Division of Urology, School of Medicine, University of Campinas, Campinas, Sao Paulo, Brazil

\begin{abstract}
Objective: To evaluate the reliability and responsiveness (internal and external) of the Portuguese version of the ICIQ-SF. We assessed the responsiveness of the ICIQ-SF after surgical procedures for the treatment of stress urinary incontinence.

Materials and Methods: Prospective open label study in 2 tertiary referral centers. Sixty-one patients of both genders (54 female and 7 male) were enrolled. Patients were treated using surgical procedures, mostly with synthetic sling $(82 \%)$. Patients were assessed before surgery and at least 1 month postoperatively using the ICIQ-SF in its translated and validated Portuguese version. Patients also underwent pre-operative urodynamic tests, Stamey incontinence grading and pad usage assessments. After surgery, patients underwent stress tests, Stamey incontinence grading and pad usage assessments.

Results: The mean age was $57.2( \pm 11.6)$ years and the mean duration of follow-up was 7.2 months $( \pm 4.5)$. Objective parameters such as urodynamic tests (by means of VLPP) and pad usage had significant correlation with changes in post-treatment scores on the ICIQ-SF $(p=0.0062$ and $p<$ 0.0001 respectively). The responsiveness expressed in terms of standardized effect sizes (SES) and standardized response means (SRM) was large for both questionnaires $(\mathrm{p}<0.0001)$.

Conclusion: The results showed high responsiveness (large effect sizes I and II) for the Portuguese version of the ICIQ-SF, indicating that this instrument is suitable for measuring outcomes in clinical trials for Brazilian patients with stress urinary incontinence.
\end{abstract}

Key words: urinary incontinence, stress; urodynamics; prostheses and implants; quality of life; questionnaires

Int Braz J Urol. 2005; 31: 482-90

\section{INTRODUCTION}

Patient-reported outcomes including symptoms, functional status and perceived quality of life (QoL) are increasingly used alongside objective clini- cal measurements to monitor the course of urinary incontinence (UI) and its treatment. Treatment outcomes, as perceived and reported by patients, complement clinical evidence and judgment of efficacy and effectiveness. A number of measures have been de- 
veloped to assess the perceived impact of UI, particularly for women, who report symptoms consistent with UI prevalence estimates of between 10\% and 30\% (1). The King's Health Questionnaire (KHQ) (2) was the first QoL questionnaire translated and validated into Portuguese in Brazil (3). The International Consultation on Incontinence Questionnaire-Short Form (ICIQ-SF) (4) is a brief instrument used to assess the impact of UI in patients' lives. It has been recently translated into Portuguese and its psychometric parameters, such as validity and reliability, have already been assessed (APPENDIX) (5). The usefulness of instruments designed to measure changes within individuals over time is dependent not only on their reliability and validity, but also on their ability to detect minimal clinically important differences. This psychometric property is called "responsiveness" (6). Responsiveness to the KHQ in its Portuguese version has just been assessed (7). According to Norman et al. (8), there has been an increasing emphasis on responsiveness as an essential characteristic for the use of health-related quality of life measures in studies of therapeutic interventions. The necessity for distinguishing between responsiveness and validity remains because an instrument can be valid and still fail to detect clinically important changes when they occur (9).

Based on the simple construct that "the goal of any therapy is to effect change in health status", our aim was to determine whether the Portuguese version of the ICIQ-SF can be considered reliable before and after treatment, and whether it is sensitive to change in continence status over time (internal and external responsiveness) following surgery to treat genuine stress incontinence (GSI).

\section{MATERIALS AND METHODS}

\section{Patients}

A total of 61 consecutive patients of both genders complaining of stress urinary incontinence that had been urodynamically diagnosed before treatment. The patients were chosen from two tertiary referral centers (seven male and nine female patients from the first tertiary referral center; 45 female patients from the second tertiary referral center) for this prospective open label study. Eligibility criteria included patients aged over 18 years old who were undergoing surgery for stress urinary incontinence with at least one month of follow up. Patients who were pregnant or currently breastfeeding or who had clinically severe cognitive dysfunction were not enrolled in the study.

\section{Methods}

Patients who underwent surgical procedures to treat stress urinary incontinence between September/2003 and November/2004 in both centers were enrolled. They were assessed by subjective and objective parameters, as well as by analysis of the $\mathrm{QoL}$ and incontinence impact using the ICIQ-SF.

\section{Measures}

Subjective parameters: Stamey incontinence grading (10) $(0=$ cured; $1=$ leakage with stressful activities (coughing, sneezing); 2 = leakage with minimally stressful activities (e.g. walking); 3 = leakage at all times, with any activity) and QoL impact on patients' lives evaluated with the Portuguese version of the ICIQ-SF.

Objective parameters: urodynamic test Valsalva leak point pressure (VLPP) (Uromaster, Dynamed/Brazil), according to the standard protocol (11) and analysis of pad usage (yes/no). If pads were used, the frequency of their usage was recorded $(0=$ no use; $1=1-2$ units/day; $2=3-4 \mathrm{u} / \mathrm{d}$ and $3=4 \mathrm{u} / \mathrm{d}$ ). If patient stated no leakage at all during the postoperative period, no further urodynamic testing was performed.

\section{Outcome Standardization}

Stress urinary incontinence was defined as the involuntary leakage of urine during coughing, sneezing or physical exertion. To assess objective outcomes such as stress test after surgical procedure, all the patients were in standing position with the physiological bladder filled to maximum vesical capacity (strong desire or sensation to void without urge). Patients were asked to perform repeated coughing and Valsalva maneuvers. Any transurethral urine 
leakage (even drops) was recorded as an objective failure of the surgical procedure and the patients underwent urodynamic testing. The patients were also asked to re-rate their QoL assessment according to ICIQ-SF after at least one-month follow-up.

\section{Quality of Life Questionnaire}

The International Consultation on Incontinence Questionnaire - Short Form (ICIQ-SF) is a simple and brief self-administered questionnaire used to assess the level and impact on QoL of urinary incontinence specifically. It is comprised of 3 questions regarding frequency, severity and QoL impact of the UI along with an eight-item scale, which assess the possible causes or situations related to UI. The ICIQSF final score is the result of the total of the scores from questions 3, 4 and 5.

\section{Psychometric Properties Evaluation}

\section{Reliability}

Cronbach's alpha was calculated by using pre- and post-treatment data to assess internal consistency, which is considered the degree of association between the items and scale scores. A minimum value of 0.70 for group comparison was desirable.

\section{Responsiveness}

Responsiveness refers to an instrument's ability to detect change (improvement or deterioration) that occurs as a result of therapy or disease progression. Participants who have an indication of clinical change, whether improvement or deterioration, should have a parallel change in their scale scores, while participants who show no change should have stable scale scores (12). Internal responsiveness is the ability of a measurement to change over a particular pre-specified time frame. External responsiveness reflects the extent to which changes in a measurement over a specified time frame relate to corresponding changes in a reference measurement of health status (13).

\section{Statistical Analysis}

To assess ICIQ-SF reliability, standardized Cronbach's alpha was used. The assessment of inter- nal responsiveness involves statistical estimation of the size of the effect; i.e. an estimate of the magnitude of the change in health status (13). Standardized effect size (SES or ES I) and standardized response mean (SRM or ES II) provide a standardized measurement of the change in score from an instrument. Both SES and SRM can be considered large $(>0.80)$, moderate $(0.5-0.8)$ or small $(<0.5)(13)$. The Exact Mann-Whitney U - test for independent groups was used to compare ICIQ-SF final scores to pad usage and VLPP (external responsiveness). The McNemar test was used to assess significant changes between proportions. Wilcoxon's signed rank test was used to compare the scores between follow-up and baseline. Statistical tests were considered significant at the 5\% level.

The software used was SAS (System for Windows - Statistical Analysis System), version 8.2 (SAS Institute Inc., 1999-2001, Cary, NC, USA). The statistical analysis was based on recommendations by Husted et al. (13), Conover (14) and Fleiss (15).

\section{Ethical Approval}

The study obtained prior approval from the Ethical Committee of the Medical Sciences School, Unicamp (No. 261/2001). All the participants signed the informed consent statement before being included in this study.

\section{RESULTS}

The socio-demographic characteristics of the ICIQ-SF sample population are displayed in Table-1. Forty-six female (75.4\%) and 4 male patients $(6.6 \%)$ underwent synthetic sling procedures; 7 female patients $(11.5 \%)$ underwent classic sling procedures; 1 female and 3 male patients $(1.7 \%$ and $4.9 \%$ respectively) underwent periurethral injection therapy. The mean Valsalva leak point pressure (VLPP $\pm \mathrm{SD}$ ) was $80.5 \pm 31.9 \mathrm{~cm} \mathrm{H}_{2} \mathrm{O}$. The mean length of follow-up was 7.2 months $(\mathrm{SD}= \pm$ $4.5)$.

The studies of ICIQ-SF reliability by means of Cronbach's alpha, before and after treatment, were 0.85 and 0.95 respectively. 
Table 1 - Background data on sample population assessed by ICIQ-SF.

\begin{tabular}{llr}
\hline Variable & Category & $\mathbf{N}(\boldsymbol{\%})$ \\
\hline Gender & Female & $54(88.5 \%)$ \\
& Male & $7(11.5 \%)$ \\
Age $($ mean \pm SD) & & $57.2(11.6)$ \\
Race & & \\
& & \\
& Caucasian & $49(80.3)$ \\
& Black & $9(14.7)$ \\
Literacy & Brown & $3(5)$ \\
& & \\
& Illiterate & $10(16.4)$ \\
& Incomplete elementary school & $32(52.5)$ \\
& Complete elementary school & $8(13.2)$ \\
& High School & $10(16.4)$ \\
& College & $1(1.5)$ \\
\hline
\end{tabular}

The great majority of the patients (58 or $95.1 \%$ ) had a negative stress test after surgical treatment for stress urinary incontinence.

A total of 54 out of 61 patients $(88.5 \%)$ who filled out the ICIQ-SF considered themselves cured after surgical treatment $(\mathrm{p}<0.0001$, Wilcoxon's signed rank test).

Fifty $(82 \%)$ out of 61 patients used pads before surgical treatment. After the procedure only 4
$(6.6 \%)$ were still using them $(\mathrm{p}<0.0001$, McNemar test).

Twenty-five out of 61 patients (41\%) changed at least 3 pads per day before treatment. Nevertheless, 57 patients $(93.5 \%)$ did not use pads at all after surgery.

\section{Responsiveness Study}

The study of the internal responsiveness for ICIQ-SF is shown in Table-2. The internal respon-

Table 2 - Comparison between pre and postoperative scores of the ICIQ-SF and internal responsiveness study (sensitivity to change), using effect size I (SES) and effect size II (SRM), $N=61$.

\begin{tabular}{lccccc}
\hline & $\begin{array}{c}\text { Preop Score } \\
\text { Mean } \pm \text { SD }\end{array}$ & Postop Score & P value* & SES & SRM \\
\hline Question 3 & $3.6 \pm 1.2$ & $0.3 \pm 0.6$ & 0.0001 & -3.11 & -3.04 \\
Question 4 & $4.0 \pm 1.8$ & $0.5 \pm 1.0$ & & & \\
Question 5 & $7.7 \pm 2.1$ & $0.6 \pm 1.2$ & & & \\
General score & $15.3 \pm 4.5$ & $1.4 \pm 2.7$ & & & \\
\hline
\end{tabular}

* Wilcoxon's signed rank test 
siveness was quantified using standardized effect size (SES or ES I) and standardized response mean (SRM or ES II), which demonstrated a large effect size. Comparison between pre- and post-operative scores of the ICIQ-SF is also shown in Table-2. We found statistically significant differences between pre- and post-treatment ICIQ-SF scores ( $<$ 0.0001). Similar results were found from the study of external responsiveness when the post-treatment final score was compared with an external variable such as pad usage and stress test (Table-3).

\section{COMMENTS}

This study investigated the reliability and responsiveness of the ICIQ-SF in Portuguese. Although it was not our main goal, we have now compared the results from the ICIQ-SF responsiveness study with the results from the just-published paper assessing the responsiveness of the Portuguese version of the King's Health Questionnaire.

Nowadays, Quality of Life questionnaires are considered to be one of the most important outcome measures in many clinical studies. Traditionally, there is a consensus that newly developed instruments should be tested for validity and reliability before they can be used in clinical trials. For evaluative instruments designed to measure longitudinal changes in health-related quality of life over time, responsiveness has been proposed as a third requirement (16).
The ICIQ-SF has just been validated and translated into Portuguese (5). The King's Health Questionnaire differs from the ICIQ-SF in many aspects. KHQ was designed for female patients only and assesses the impact of UI in eight domains of the patients' lives. The more comprehensive instrument is, more detailed is the health profile it provides (2). Contrarily, ICIQ-SF is brief and simple to understand and fill in. Furthermore, it is not gender-specific like the KHQ and is intended to be universal (applicable for use in individuals of all ages, genders, backgrounds, patient groups, diagnoses and cultures). A further disadvantage of the KHQ is that it does not attempt to determine clearly the severity of incontinence in terms of the frequency or amount of leakage. In addition, the KHQ has received limited use outside of clinical settings. Conversely, the ICIQ$\mathrm{SF}$ is intended to be brief yet comprehensive enough for use in assessing incontinence and serves as an outcome measure in clinical trials and other research to assess the efficacy of interventions. Moreover, it is suitable for use as an epidemiological tool to determine the distribution of incontinence in populations around the world, allowing international multicenter studies to be made (4). One of the criticisms of the QoL assessment by ICIQ-SF is that the QoL construct is based on one question in a 10-item scale to quantify the burden of urinary incontinence in the perceived quality of a patient's life. It is to be used as a visual analog scale (VAS) where the patients can choose the degree of interference from UI in their lives by ticking or circling a number on a

Table 3 - Study of the external responsiveness of the ICIQ-SF comparing post-treatment questionnaire final score, pad usage and VLPP.

\begin{tabular}{llrlll}
\hline Variable & Category & N & Mean & 土SD & P value** $^{*}$ \\
\hline Pad usage & No & 57 & 1.0 & 2.2 & $<0.0001$ \\
& Yes & 4 & 7.3 & 2.6 & 0.0062 \\
Stress test & Negative & 58 & 1.2 & 2.6 & 0.6 \\
& Positive & 3 & 5.7 & & \\
\hline
\end{tabular}

***act Mann-Whitney Test 
scale ranging from zero to ten (when zero is considered "not interfere at all" and 10 represents "interfere a lot").

According to De Boer et al. (17), their study assessing the role of VAS as a valid and reliable tool for the study of QoL in clinical practice and research found that VAS could be considered a good instrument when compared to multi-item questionnaires. Based on their results, they recommend its use as a global quality of life measure in clinical trials. Indeed, most QoL questionnaires are composed of many items divided into several domains - such as role and physical limitation, personal relationships, emotion, among others. The criticisms of these questionnaires are that they are time-consuming and difficult to use outside clinical settings. Contrarily, the brevity of the ICIQ-SF enables it to be used without greatly increasing the burden on the respondents.

As shown in Table-1, 10 patients $(16.4 \%)$ were illiterate and an interviewer read the question to ensure important data was not missed. According to data from the 2000 Census (18), the illiteracy rate for Brazilian people of both sexes aged 15 or over is $13.3 \%$, and the mean length of schooling was 5.7 years. Comparing the mean level of schooling of our population sample with the literacy level for the whole Brazilian population, it can be seen that our sample had almost the same overall rate of literacy. These patients were considered unable to understand the questions, so we chose to have the questionnaire read out loud (without explanation of the questions) by a nursing professional who was trained for this task. In our environment, such a procedure is normal, especially in studies that utilize scales. It should be added that, after comparing different methods of administering questionnaires, Weinberger et al. (19) concluded that $70 \%$ of the patients preferred interviews and $20 \%$ the self-administered forms.

Reliability as measured by Cronbach's Alpha showed a good to excellent degree of association between the scale scores before and after treatment.

Internal responsiveness expressed in terms of the SES and the SRM (Table-2) showed large values for effect size studies for all ICIQ-SF scores. This study highlighted that ICIQ-SF was strongly sensi- tive to change, enabling it to be used as an important tool in clinical practice or research.

As shown in Table-3 (external responsiveness study), there was a good correlation between the ICIQ-SF general score after treatment regarding pad usage analysis. The ICIQ-SF general score showed a significant difference when the two groups (yes/no) were compared ( $p<0.0001)$. Similar results were found when the ICIQ-SF scores were also compared to the post-treatment analysis of Stress test $(p=0.0062)$, showing excellent external responsiveness.

These results are in line to the responsiveness study of KHQ, which yielded good results from the assessed parameters, for both internal and external responsiveness, apart from having excellent reliability (7).

Beaton et al. (20) proposed a new taxonomy for responsiveness based not only on statistical characteristics such as "large effect sizes" but also on a very highly contextualized attribute of an instrument. There are three axes (questions) underlying the new classification system: "who is being analyzed?" (individuals or groups); "which scores are being contrasted?" (over time / one point in time); and "Which type of change is being quantified?" (for example, observed change over important change). So, a questionnaire could, thus, be described as being "responsive to" a given category in this new taxonomy.

The present study demonstrates the relevance of quality of life to the assessed clinical condition. The performance of the ICIQ-SF in this clinical trial suggests that it can be an important addition to the compendium of outcome measures used to assess UI and its treatment. Both ICIQ-SF and KHQ are now available for use in clinical practice and research in Brazil. Our next aim is to check ICIQ-SF sensitivity in a large community-based population epidemiological study, as it is also intended to be used.

In conclusion, the ICIQ-SF appears to capture changes, i.e. it has good internal and external responsiveness. Although brief, it seemed to be robust in the whole study of responsiveness, showing large effect size and excellent correlation with clinical and surgical outcome 
APPENDIX - ICIQ - SF in Portuguese.

\section{ICIQ-SF EM PORTUGUÊS}

Nome do Paciente:

Data de Hoje:

Muitas pessoas perdem urina alguma vez. Estamos tentando descobrir quantas pessoas perdem urina e o quanto isso as aborrece. Ficariamos agradecidos se você pudesse nos responder as seguintes perguntas, pensando em como você tem passado, em média nas ÚLTIMAS QUATRO SEMANAS.

1. Data de Nascimento:__.____________ (Dia / Mês / Ano)

2. Sexo: Feminimo $\square \quad$ Masculino $\square$

3. Com que freqüência você perde urina? (assinale uma resposta)

$\begin{aligned} \text { Nunca } & 0 \\ \text { Uma vez por semana ou menos } \square & 1 \\ \text { Duas ou três vezes por semana } \square & 2 \\ \text { Uma vez ao dia } \square & 3 \\ \text { Diversas vezes ao dia } & 4 \\ \text { O tempo todo } \square & 5\end{aligned}$

4. Gostariamos de saber a quantidade de urina que você pensa que perde. (assinale uma resposta)

Nenhuma $\square 0$
Uma pequena quantidade $\square 2$
Uma moderada quantidade $\square 4$
Uma grande quantidade $\square 6$

5. Em geral, quanto que perder urina interfere em sua vida diária? Por favor, circule um número entre 0 (não interfere) e 10 (interfere muito)

$\begin{array}{lccccccccc}0 & 1 & 2 & 3 & 4 & 5 & 6 & 7 & 8 & 9 \\ \text { Nào interfere } & & & & & & & & \begin{array}{r}10 \\ \text { Interfere muito }\end{array}\end{array}$

ICIQ Escore: soma dos resultados $3+4+5=$

6. Quando você perde urina?

(Por favor, assinale todas as alternativas que se aplicam a você).

Perco antes de chegar ao banheiro

Perco quando tusso ou espirro

Perco quando estou dormindo

Perco quando estou fazendo atividades físicas

Perco quando terminei de urinar e estou me vestindo

Perco sem razão óbvia Perco o tempo todo

"Obrigado por você ter respondido as questões" 


\section{REFERENCES}

1. Patrick DL, Martin ML, Bushnell DM, Yalcin I, Wagner TH, Buesching DP: Quality of life of women with urinary incontinence: further development of the incontinence quality of life instrument (I-QOL). Urology. 1999; 53: 71-6. Erratum in: Urology 1999; 53: 1072.

2. Kelleher CJ, Cardozo LD, Khullar V, Salvatore S: A new questionnaire to assess the quality of life of urinary incontinent women. Br J Obstet Gynaecol. 1997; 104: 1374-9.

3. Tamanini JT, D'Ancona CA, Botega NJ, Rodrigues Netto N Jr: Validation of the Portuguese version of the King's Health Questionnaire for urinary incontinent women. Rev Saude Publica. 2003; 37: 203-11.

4. Avery K, Donovan J, Abrams P: Validation of a new questionnaire for incontinence: the International Consultation on Incontinence Questionnaire (ICIQ). Abstract no. 86 of the International Continence Society 31 st annual meeting. Seoul, Korea. Neurourol Urodyn. 2001; 20: 510-1.

5. Tamanini JT, Dambros M, D'Ancona CA, Palma PC, Rodrigues Netto N Jr: Validation of the "International Consultation on Incontinence Questionnaire - Short Form" (ICIQ-SF) for Portuguese. Rev Saude Publica. 2004; 38: 438-44.

6. Guyatt G, Walter S, Norman G: Measuring change over time: assessing the usefulness of evaluative instruments. J Chronic Dis. 1987; 40: 171-8.

7. Tamanini JT, Dambros M, D'Ancona CA, Palma PC, Botega NJ, Rios LA, et al.: Concurrent validity, internal consistency and responsiveness of the Portuguese version of the King's Health Questionnaire (KHQ) in women after stress urinary incontinence surgery. Int Braz J Urol. 2004; 30: 479-86.

8. Norman GR, Stratford P, Regehr G: Methodological problems in the retrospective computation of responsiveness to change: the lesson of Cronbach. J Clin Epidemiol. 1997; 50: 869-79.

9. Guyatt GH, Deyo RA, Charlson M, Levine MN, Mitchell A: Responsiveness and validity in health status measurement: a clarification. J Clin Epidemiol. 1989; 42: 403-8.

10. Stamey TA: Urinary Incontinence in the Female. In: Campbell's Urology, 4th ed., Harrison JH, Guittes RF, Perlmutter AD (eds.). Philadelphia, WB Saunders. 1979; pp. 2272-93.

11. Nitti VW, Combs AJ: Correlation of Valsalva leak point pressure with subjective degree of stress urinary incontinence in women. J Urol. 1996; 155: 281-5.
12. Lubeck DP, Prebil LA, Peeples P, Brown JS: A health related quality of life measure for use in patients wht urge urinary incontinence: A validation study. Qual Life Res. 1999; 8: 337-44.

13. Husted JA, Cook RJ, Farewell VT, Gladman DD: Methods for assessing responsiveness: a critical review and recommendations. J Clin Epidemiol. 2000; 53: 459-68.

14. Conover WJ: Practical Nonparametric Statistics. In: Contingency Tables and the Use of Ranks. New York. John Wiley \& Sons. 1971; pp. 140-281.

15. Fleiss, JL Statistical Methods for Rates and Proportions. 2nd ed. New York. John Wiley \& Sons. 1981; pp 212-22.

16. Terwee CB, Dekker FW, Wiersinga WM, Prummel MF, Bossuy PM: On assessing responsiveness of healthrelated quality of life instruments: guidelines for instrument evaluation. Qual Life Res. 2003; 12: 34962.

17. de Boer AG, van Lanschot JJ, Stalmeier PF, van Sandick JW, Hulscher JB, de Haes JC, et al.: Is a singleitem visual analogue scale as valid, reliable and responsive as multi-item scales in measuring quality of life? Qual Life Res. 2004; 13: 311-20.

18. IBGE Foundation (Brazilian Institute of Geography and Statistics). Minimal Social Indicators: Demographic Aspects - General Information. 1999. Available at http://www.ibge.gov.br/home/estatistica/ populacao/condicaodevida/indicadoresminimos/ tabela3.shtm [in Portuguese]

19. Weinberger M, Oddone EZ, Sansa GP, Sandsman PB: Are health-related quality of life measures affected by the mode of administration? J Clin Epidemiol. 1996; 49: 135-40.

20. Beaton DE, Bombardier C, Katz JN, Wright JG: A taxonomy for responsiveness. J Clin Epidemiol. 2001; 54: 1204-17.

Received: February 2, 2005 Accepted after revision: May 3, 2005

\footnotetext{
$\overline{\text { Correspondence address: }}$

Dr. Jose Tadeu Nunes Tamanini

Rua Floriano Peixoto, 443

Jau, SP, 17201-100, Brazil

Fax: + 5514 3621-1829

E-mail: tadeutamanini@jau.flash.tv.br
} 


\section{EDITORIAL COMMENT}

In order to incorporate in a single questionnaire the most relevant aspects of urinary incontinence and its impact on quality of life, the ICIQ, which is more widely used in research studies, was summarized in the ICIQ-SF format, which is directed to clinical application in the daily practice. The three questions on the ICIQ-SF consistently assess frequency, severity and impact on quality of life caused by urinary incontinence. It can be applied to patients of both genders, either young or elderly. Since 2001, it has been validated in several other countries with a native language different from English, such as Spain and Japan $(1,2)$.

Its recent validation for Portuguese was clearly important since it allows the use of this assessment tool in studies on urinary incontinence conducted in Brazil, thus enabling the comparison between results obtained here with those published in urologic international literature.

The present study, which was prospectively performed at two tertiary referral centers, verified the responsiveness of ICIQ-SF, which was applied to patients undergoing surgical treatment for urinary incontinence. The positive correlation between urodynamic findings and e pad test and ICIQ-SF values, as well as its responsiveness with a high level of statistical significance, confirmed the applicability of this questionnaire in its Portuguese version.

Another significant aspect regarding the ICIQ-SF questionnaire is the recent demonstration (3) of equivalence in results - both when it is self-applied (according to its initial proposal) and when it is completed by the physician. This fact is important in our environment where a great deal of patients can have difficulties in interpreting and completing the questionnaire.

\section{REFERENCES}

1. Espuna Pons M, Rebollo Alvarez P, Puig Clota M: Validation of the Spanish version of the International Consultation on Incontinence Questionnaire-Short Form. A questionnaire for assessing the urinary incontinence. Med Clin (Barc). 2004; 122: 288-92.

2. Terai A, Ueda N, Utsunomiya N, Kouhei N, Ichioka $\mathrm{K}$, Yoshimura K: Effect of urinary incontinence on lower urinary tract symptoms in Japanese women. Urology. 2004; 64: 1139-43.

3. Hajebrahimi S, Corcos J, Lemieux MC: International consultation on incontinence questionnaire short form: comparison of physician versus patient completion and immediate and delayed self-administration. Urology. 2004; 63: 1076-8.

Dr.José Carlos Truzzi

Division of Urology Santo Amaro University - UNISA

São Paulo, SP, Brasil E-mail: jctruzzi@hotmail.com 